\title{
Development and Life Cycle Assessment of Polyester Binders Containing 2,5-Furandicarboxylic Acid and Their Polyurethane Coatings
}

\author{
María Nelly García González ${ }^{1,2} \cdot$ Pål Börjesson $^{2} \cdot$ Marinella Levi $^{1}$ · Stefano Turri ${ }^{1}$
}

Published online: 9 May 2018

(c) The Author(s) 2018

\begin{abstract}
This work presents a new polyester binder based on 2,5-furandicarboxylic acid (FDCA) as precursors of polyurethane (PU) coatings. The new $100 \%$ bio-based structure is composed of four different monomers such as glycerine (Gly), 1,3-propanediol (1,3-PD), 2,5-furandicarboxylic acid (FDCA) and succinic acid (SA). The corresponding PU coating was obtained by crosslinking with a conventional polyisocyanate (Vestanat 1890/100). Evaluation of technological performances is present and benchmarked against partially bio-based (75\% renewable carbon) polyester binder and fossil-based polyester binder, already developed in one of our previous work. The study showed a stiffer PU coating and a more hydrophilic character leading to better adhesion where a possible potential application may be interesting as an intermediate layer/primer in the field of metal coating (coil coating, automotive). Afterwards, the evaluation of the total impact of greenhouse gas emissions (GHG), the total non-renewable energy use (NREU) by the Life Cycle Assessment (LCA) for the new polyester binder are included on a cradle-to-gate approach, and considering an FDCA production process starting from sugar beet (primary data). The results showed a very noteworthy reduction in terms of GHG emissions ( -36 and $-79 \%)$ and a noticeable reduction impact in terms of NREU ( -38 and $-60 \%$ ) compared to $75 \%$ bio-based and fossil-based polyester binders respectively. Moreover, a sensitivity analysis regarding sugar production from beet cultivation was developed through different LCA calculation methodologies. Those methodologies showed a not very significant difference between them.
\end{abstract}

\section{Graphical Abstract}

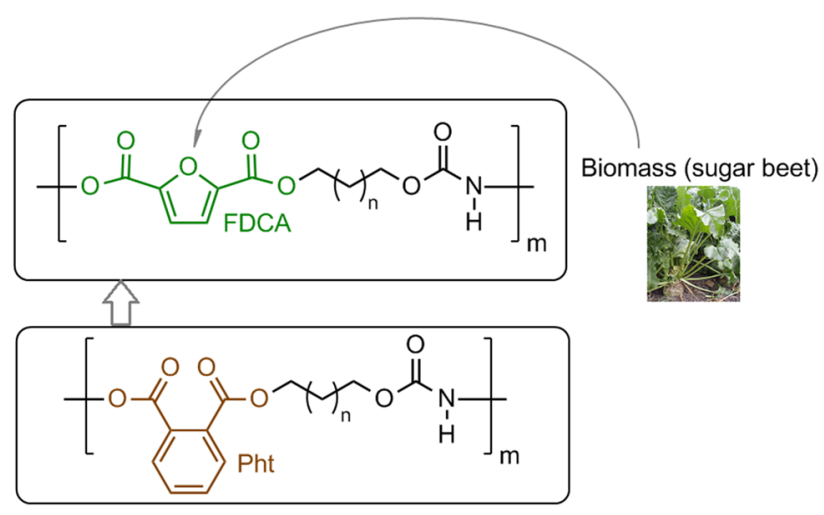

Electronic supplementary material The online version of this article (https://doi.org/10.1007/s10924-018-1234-3) contains supplementary material, which is available to authorized users.

Extended author information available on the last page of the article 
Keywords Life cycle assessment · 2,5-Furandicarboxylic acid · Bio-based monomers · Bio-based polyester · Polyurethane coating

\section{Introduction}

Polyurethanes (PUs) are one of the most used coating materials in many manufacturing sectors (automotive, furniture, heavy duty) due to their excellent durability and mechanical properties [1]. PUs are actually the sixth most used polymer on a global scale with an annual production of over 12 million tons [2]. One of the emerging topics in modern PU technology is the exploitation of monomers and macromers from renewable resources to improve the environmental sustainability while preserving the excellent technical performances [3, 4]. In fact, many works on bio-based PU coatings have appeared in literature for different applications $[5,6]$. PU coatings are obtained by the stoichiometrically balanced mixture and crosslinking of polyols (polyether and frequently polyester oligomers) with polyisocyanates. By a careful selection of different polyols and isocyanates, a variety of PUs with specific properties can be developed for a broad range of industrial applications like foams, paints, thermoplastics, fibers and adhesives [7-9].

Polyester polyols are the largest fraction in the composition of PU coating material. They are made from aliphatic as well as aromatic diacids and hydroxy functional monomers [10]. Within aromatic acids, 2,5-furandicarboxylic acid (FDCA) is a relatively "new" bio-based building block with a unique structure that is attracting great interest. Actually, it is the only substance containing aromatics among the top 12 bio-derived chemicals listed by the U.S. Department of Energy (DOE) in 2004 and updated in 2010 [11]. Although FDCA could be produced from cellulose or hemicellulose, the production of furan derivatives from sugars, synthesized chemically from 5-hydroxymethylfurfural (HMF), has recently become a promising route in green chemistry and in catalysis studies [12]. In recent years, polyester polymers and copolymers based on FDCA have received special attention in many aspects regarding monomer synthesis, polymerization reactions, application $[13,14]$ and characterization [15-17]. FDCA was mainly proposed as a green alternative to petrochemical-derived terephthalic acid to produce thermoplastic polyesters [18, 19]. A recent paper [20] presented an overview of the developments and future prospects on bio-based polyesters from FDCA and other renewable resources. They can be used as biomaterials [21] with competitive properties [22] and potential applications as thermoplastics as well as elastomers [23].

In spite of the high industrial interest, only a few papers are available in the open literature [24, 25] concerning the evaluation of environmental impacts related to FDCA production. The work by Isola et al. [25] reported the application of the LCA model for the laboratory-scale production from the conversion of fructose to HMF, FDCA monomer, the corresponding polymer, its recycling and the total impacts are observed individually. However, the laboratory-scale evaluation of consumables led to an overall high total impact in many different categories, such as the climate change. Eerhart's work was focused on the LCA of the production of polyethylene furandicarboxylate (PEF) using furanics as intermediates, starting from corn based fructose, and evaluating the non-renewable energy use (NREU) and greenhouse gas (GHG) impacts. This LCA study has become, so far, the only available one at industrial scale where the different steps for FDCA production are considered.

Most of the studies concerning FDCA-based polyesters are about thermoplastics, but there is a lack of information in the literature about polyester copolymers based on FDCA as precursors for PU coatings. Due to this, the main objective of this work is to present a new class of polyester binders based on FDCA suitable as precursors of PU coating materials. The new $100 \%$ bio-based structure was re-designed and obtained through the selection and copolymerization of four different monomers, all available from modern biorefinery downstreams such as glycerine (Gly), 1,3-propanediol (1,3-PD), 2,5-furandicarboxylic acid (FDCA) and succinic acid (SA). The corresponding PU coatings were obtained and their technological performances were benchmarked against partially bio-based ( $75 \%$ renewable carbon) and fossil-based polyester binders, already developed by our group and described in a previous work [26]. Moreover, the evaluation of the total impact of greenhouse gas emissions (GHG), the total non-renewable energy use (NREU) by the Life Cycle Assessment (LCA) are included on the basis of a cradle-to-gate approach separating the contributions due to the monomer mixture composition and those related to the copolymerization process, and considering a FDCA production process starting from sugar beet (primary data). Specifically, a finer analysis of the impact of marine eutrophication and freshwater eutrophication is allowed, providing relevant information about the environmental implication of the production of a chemical derived by biomass (sugar beet), as the case of the present study.

\section{Experimental Section}

\section{Materials}

All materials used in this study are commercially available. The conventional polyisocyanate used for crosslinking, 
called commercially Vestanat $1890 / 100$, was supplied by Evonik Industries. It was a cycloaliphatic polyisocyanate based on isophorone diisocyanate (IPDI). 1,2-propanediol (1,2-PD), 1,3-propanediol (1,3-PD), succinic acid (SA), adipic acid (AA), phthalic anhydride (Pht), glycerine (Gly) used for the synthesis of the polyesters and the solvents needed to reduce the viscosity such as butyl acetate (BA) and propylene carbonate (PCC) were all purchased from Sigma-Aldrich. FDCA monomer was provided by the Sinochem Jiangsu Co., Ltd. (Middle, Nanjing, China).

\section{Preparation of Sustainable PU Coating from $100 \%$ Bio-based PE Binder}

The PU coating indicated as PU1_100\% was obtained by crosslinking with a conventional polyisocyanate (IPDI) a model, 100\%-biobased 4-monomer polyester binder (named PE_100\% in the following) made by a 4-monomer copolymerization. The synthesis PE_100\% was made through a bulk polycondensation process. The monomers reported in Table 1 were charged in a three-necked glass flask and polymerization was accomplished with a progressive increase of high temperature from 150 to $210{ }^{\circ} \mathrm{C}$, under mechanical stirring at $60 \mathrm{rpm}$ and a dry nitrogen flow to remove water formed as by-product. The progress of the reaction was then checked by end group titration which monitored the residual acidity of polyesters, and the polymerization was stopped when the acid number was $<10 \mathrm{mgKOH} / \mathrm{g}$. Production and characterization of $100 \%$-biobased PE binder, partially biobased PE_75\% binder and fossilbased PE_Fossil binder are reported in this study. Characterization consisted in thermal analysis by differential scanning calorimetry (DSC) and molecular weight measurement by gel permeation chromatography (GPC). The coatings were obtained by formulation of the selected polyester and the appropriate amount of isocyanate crosslinker in a $30 \%$ solid solution in propylene carbonate, together with a $\mathrm{OH} /$ $\mathrm{NCO}$ stoichiometric ratio $=1.03$; the catalyst 1,4 -Diazabicyclo [2.2.2] octane (DABCO) was added in amount of $0.5 \% \mathrm{w} / \mathrm{w}$. The final PU1 coating was applied onto glass and aluminium panels and cured in an oven at $100{ }^{\circ} \mathrm{C}$ for $1 \mathrm{~h}$, obtaining a dry film thickness of $20-30 \mathrm{~mm}$. The extent of reaction upon crosslinking was checked by monitoring the progressive disappearance of the NCO band through IR spectroscopy (stretching band at $2260 \mathrm{~cm}^{-1}$ ). Results were compared to PU2_75\% (from PE_75\%) and PU3_Fossil (from PE_Fossil) which were reported in our previous work [26]. For PU2_75\% and PU3_Fossil, butyl acetate (BA) was used as dilution solvent. All coatings passed the chemical resistance test after curing (MEK test, $>100$ double rubs according to ASTM D4752 [27]) confirming that crosslinking has occurred.

Table 1 shows the composition of the two bio-based polyester binders and the source for the evaluation of their ecoprofiles. The composition and source of the fossil-based polyester binder was reported in our previous work [26], and its structure was formed by glycerine (Gly), 1,2-propanediol (1,2-PD), phthalic anhydride (Pht) and adipic acid (AA). The only difference between the two bio-based materials under consideration (PU1 and PU2) is in the nature of the aromatic acid, with replacement of fossil-based phthalic acid and bio-based FDCA passing from PE_75\% / PU2 to PE_100\% / PU1systems. The characterization of the PU films consisted in thermal analysis by differential scanning calorimetry (DSC), surface wettability by a static optical contact angle (OCA) against water, adhesion by pull-off tests (ASTM D4541-09), indentation hardness by Buchholtz test (ISO 2815) and surface tension by a static optical contact angle (OCA) against water and diiodomethane. Hydrolytic stability was also tested by exposing the coatings at $60^{\circ} \mathrm{C}$, $100 \%$ humidity for a period of 30 days. The stability test was repeated in 3 different samples for each composition. The

Table 1 Relevant information and composition of monomers for the two bio-based polyester binders

\begin{tabular}{|c|c|c|c|c|c|c|c|c|}
\hline \multirow[b]{2}{*}{ Family } & \multicolumn{4}{|c|}{ PE_75\% Garcia Gonzalez et al. [26] } & \multicolumn{4}{|c|}{ PE_100\% (Present study) } \\
\hline & Monomers & $\begin{array}{l}\text { Bio or fossil } \\
\text { based }\end{array}$ & Source & $\begin{array}{l}\text { Com- } \\
\text { position } \\
(\% \mathrm{w} / \mathrm{w})\end{array}$ & Monomers & $\begin{array}{l}\text { Bio or fossil } \\
\text { based }\end{array}$ & Source & $\begin{array}{l}\text { Com- } \\
\text { position } \\
(\% \mathrm{w} / \mathrm{w})\end{array}$ \\
\hline Polyols & Glycerine (Gly) & Bio (Palm oil) & $\begin{array}{l}\text { Secondary data } \\
{[28]}\end{array}$ & 7.00 & Glycerine (Gly) & Bio (Palm oil) & $\begin{array}{l}\text { Secondary data } \\
\text { [28] }\end{array}$ & 6.90 \\
\hline Aliphatic diols & $\begin{array}{l}\text { 1,3-propanediol } \\
\text { (1,3-PD) }\end{array}$ & $\begin{array}{l}\text { Bio (Corn } \\
\text { sugar) }\end{array}$ & $\begin{array}{l}\text { Secondary data } \\
{[29]}\end{array}$ & 34.70 & $\begin{array}{l}\text { 1,3-propanediol } \\
\text { (1,3-PD) }\end{array}$ & $\begin{array}{l}\text { Bio (Corn } \\
\text { sugar) }\end{array}$ & $\begin{array}{l}\text { Secondary data } \\
\text { [29] }\end{array}$ & 34.05 \\
\hline $\begin{array}{c}\text { Aromatic } \\
\text { diacids }\end{array}$ & $\begin{array}{l}\text { Phthalic Anhy- } \\
\text { dride (Pht) }\end{array}$ & Fossil & $\begin{array}{l}\text { Secondary data } \\
{[30]}\end{array}$ & 37.90 & $\begin{array}{l}\text { 2,5-Furandi- } \\
\text { carboxylic } \\
\text { acid } \\
\text { (FDCA) }\end{array}$ & $\begin{array}{l}\text { Bio (Sugar } \\
\text { beet) }\end{array}$ & Present study & 38.40 \\
\hline $\begin{array}{c}\text { Aliphatic } \\
\text { diacids }\end{array}$ & $\begin{array}{l}\text { Succinic acid } \\
\quad \text { (SA) }\end{array}$ & $\begin{array}{l}\text { Bio (Corn } \\
\text { starch) }\end{array}$ & $\begin{array}{l}\text { Secondary data } \\
\text { [31] }\end{array}$ & 20.40 & $\begin{array}{l}\text { Succinic acid } \\
\text { (SA) }\end{array}$ & $\begin{array}{l}\text { Bio (Corn } \\
\text { starch) }\end{array}$ & $\begin{array}{l}\text { Secondary data } \\
\text { [31] }\end{array}$ & 20.65 \\
\hline
\end{tabular}


samples were periodically monitored through contact angle and indentation hardness tests.

\section{Materials Characterization}

\section{Differential Scanning Calorimetry (DSC) analysis}

Thermal analysis was performed on PE and PU samples using a DSC (MettlerToledo DSC/823e instrument) at a scan rate of $10{ }^{\circ} \mathrm{C} \mathrm{min}^{-1}$ under nitrogen flux. The measurements consisted of three runs (heating/cooling/heating) from 25 to $150{ }^{\circ} \mathrm{C}$. The samples measured had a weight of around $10-15 \mathrm{mg}$.

\section{Optical Contact Angle (OCA)- Surface Wettability}

The wettability of the PU surfaces was studied performing contact angle measurements using an optical contact angle system (OCA-15-Plus, Dataphysics, Germany) equipped with a CCD photocamera and with a $500 \mu \mathrm{L}$ Hamilton syringe to dispense liquid droplets. Measurements were made at room temperature by means of the sessile drop technique with dedicated software (SCA 2.0) determining the contact angle based on the Young Laplace fitting method. The pure water $(\mathrm{H} 2 \mathrm{O})$ was used as probe liquid and the delivered volume was $2 \mu \mathrm{L}$ with $0.5 \mu \mathrm{L} / \mathrm{s}$ as dispense speed. A minimum of 25 measurements were taken in different regions on the surface of each PU film and results were averaged.

\section{Gel Permeation Chromatography (GPC)}

The molecular weight of PE samples was estimated by means of gel permeation chromatography (GPC) using a Waters 510 high-performance liquid chromatography (HPLC) system equipped with a Waters 486 tunable absorbance detector set at $\lambda=300 \mathrm{~nm}$, using THF as eluent. The sample ( $200 \mu \mathrm{L}$ of PE in THF, $2 \mathrm{mg} / \mathrm{mL}$ ) was injected into a system of columns connected in series (Ultrastyragel HR, Waters) and the analysis was performed at $30{ }^{\circ} \mathrm{C}$ and at a flow rate of $0.5 \mathrm{~mL} / \mathrm{min}$. The GPC system was calibrated against polystyrene standards in the $102-104 \mathrm{~g} / \mathrm{mol}$ molecular weight range.

\section{Pull-Off Adhesion Testing}

The adhesive properties of the resulting PU materials on different substrates (glass and aluminium chromed) were evaluated with a PosiTest AT-M Manual adhesion pull-off tester (DeFelsko, ASTM D4541-09 [32]) by measuring the pulling force needed to detach a $20 \mathrm{~mm}$-diameter aluminium dolly adhered to the films by means of epoxy adhesive (Araldite
2011 , curing cycle: $50{ }^{\circ} \mathrm{C}, 24 \mathrm{~h}$ ). 3 determinations of each sample were assessed.

\section{Buchholz Indentation test-Hardness Analysis}

The indentation resistance (hardness) of the corresponding PU coatings were evaluated by Indentation Hardness Tester acc. to Buchholz, Model 263 (ISO 2815 [33]). A metal block with testing force between a range of $4.90 \mathrm{~N}$ and $4.95 \mathrm{~N}$ (equivalent to 500 to $505 \mathrm{~g}$ ) was applied on each coating surface for $30 \mathrm{~s}$ and length (1) of the resulting indentation was measured using a microscope. The indentation resistance $\left(\dot{\alpha}_{\mathrm{B}}\right)$ values were obtained from the indentation length $\left(\alpha_{B}=100 / 1\right.$, where 1 is in $\left.\mathrm{mm}\right)$.

\section{Surface Characterization}

Surface tension on the corresponding coatings was evaluated by performing contact angle measurements. The procedure was followed using water $\left(\mathrm{H}_{2} \mathrm{O}\right)$ and diiodomethane $\left(\mathrm{CH}_{2} \mathrm{Cl}_{2}\right)$ (Sigma-Aldrich) to compute surface tension. The surface energies and its polar and dispersive components were estimated by Wu's harmonic-mean method [34].

\section{Life Cycle Assessment (LCA) on Polyester Binders}

\section{System Boundary}

Figure 1 shows the system boundary of the three polyester binders according to a cradle-to-factory gate view. As for the FDCA monomer, the simplified flow diagram for its production is shown in Fig. 2. The FDCA production system is divided into five major steps: sugar beet cultivation; transport of beet to the plant and the sugar production; conversion of fructose; conversion of 5-HMF and finally oxidation of 5-HMF to the FDCA. Transport of the raw materials and the production of the farm equipment, such as beet harvesters and tractors used in the sugar production step, and the intermediate transport steps from sugar production to FDCA production, were outside the system boundaries and not considered. The multiple operational steps along with the description for the sugar production from beet cultivation are shown in Supporting Information.

\section{Methodology}

This study focuses on the 'Cumulative Energy Demand' [35] (v1.09) method which covers the impact category of non-renewable energy use (NREU) including fossil and nuclear energy and the 'Greenhouse Gas Protocol (GGP)' (v1.01) method which covers the impact category of GHG emissions. The GGP method is chosen to perform a Carbon 

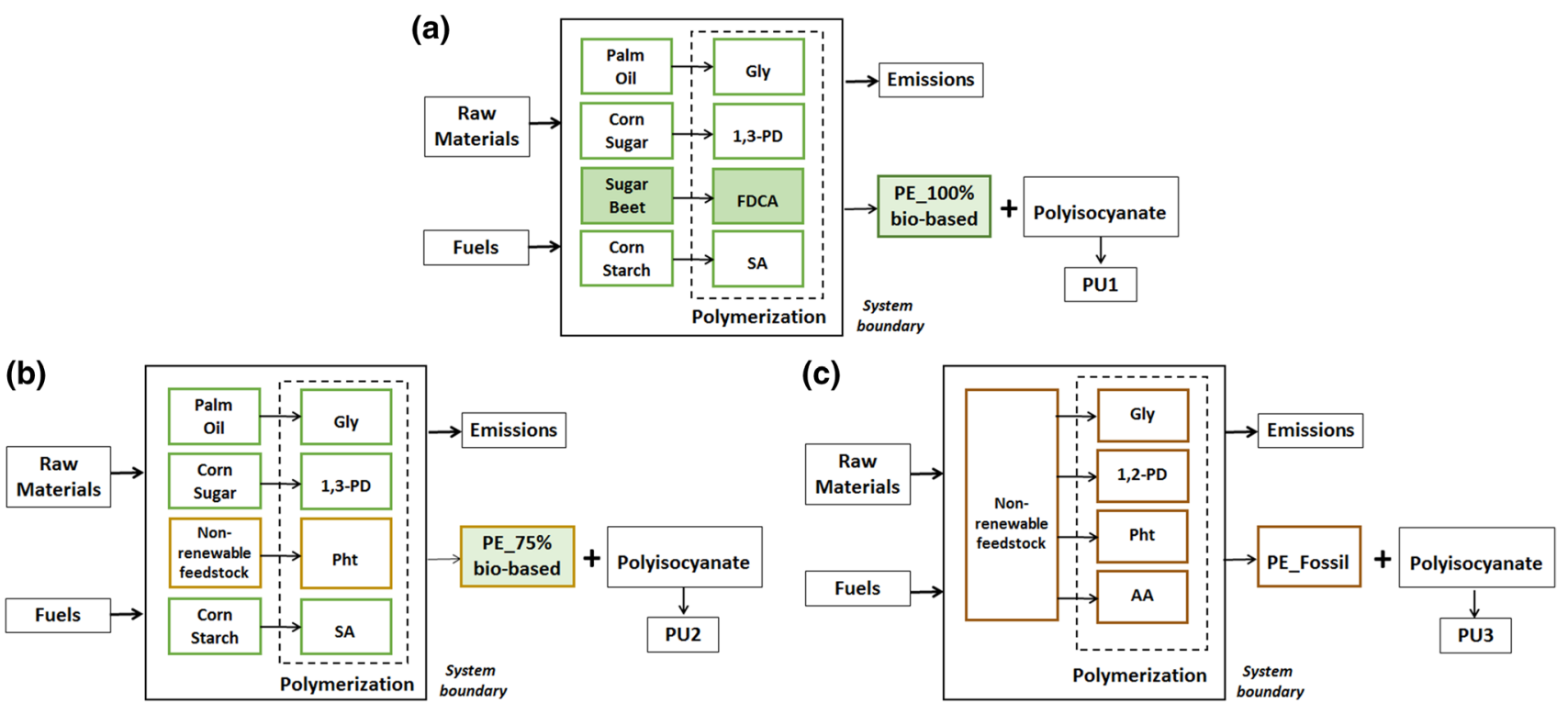

Fig. 1 The system boundary of the different polyesters: a PE_100\%, b PE_75\%, and c PE_Fossil. Green boxes represent the monomers from renewable resources for the bio-based polyester binders

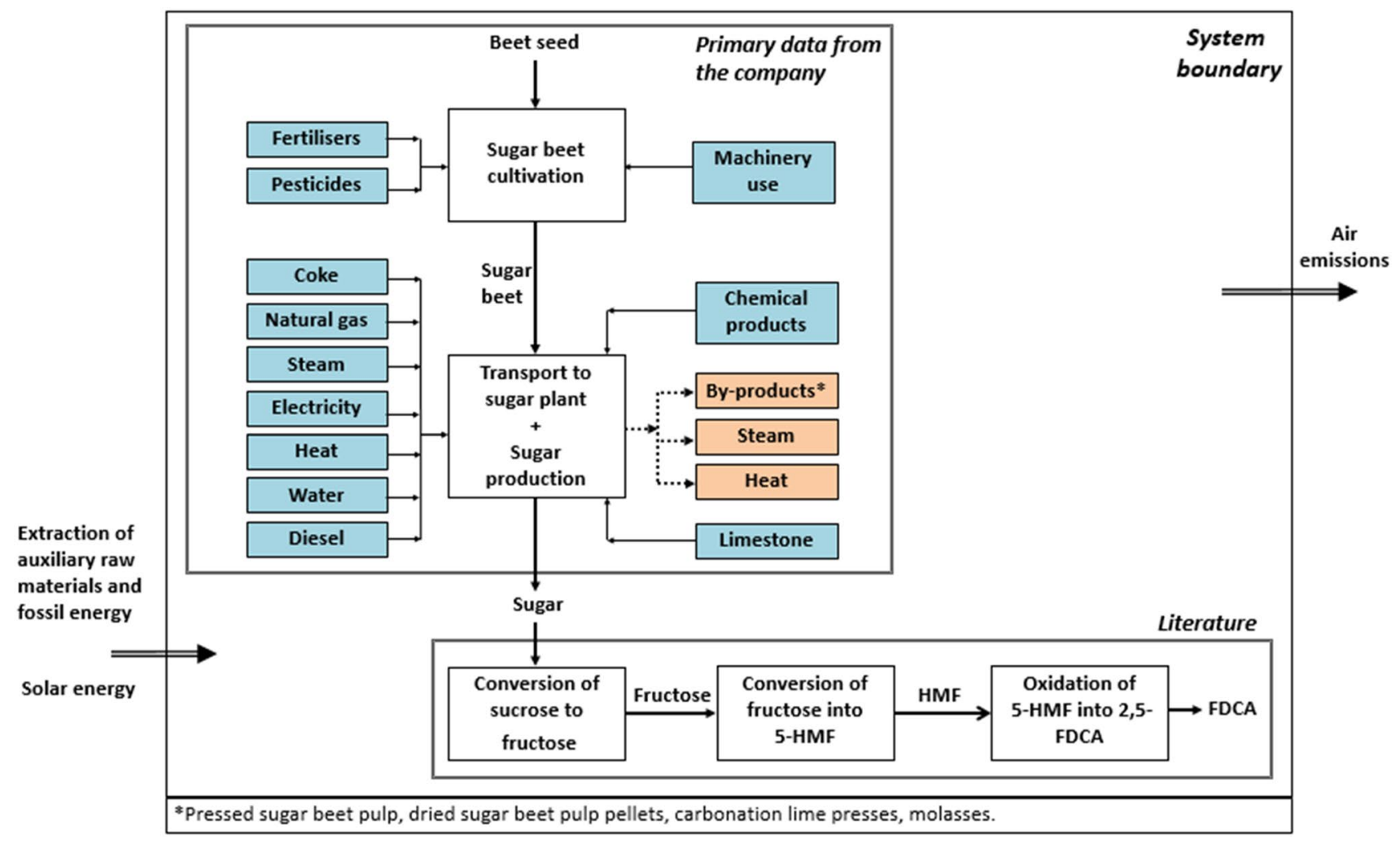

Fig. 2 The system boundary of the FDCA production from sugar beet cultivation. Blue and orange boxes represent all the relevant inputs and outputs included in sugar beet cultivation and sugar production respectively

Footprint of the different alternatives analysed. This method leads to measure the amount of greenhouse gases (in $\mathrm{kg}$ $\mathrm{CO}_{2}$ eq) emitted to the atmosphere contributing to global climate change, which includes emissions from fossil and biogenic carbon sources, emissions caused by land use change and carbon uptake by plants over a 100-year time 
horizon. To calculate carbon dioxide equivalents $\left(\mathrm{CO}_{2 \mathrm{eq}}\right)$ of all non- $\mathrm{CO}_{2}$ gases $\left(\mathrm{CH}_{4}, \mathrm{~N}_{2} \mathrm{O}, \mathrm{SF}_{6}, \mathrm{HFCs}\right.$ and $\left.\mathrm{CFCs}\right)$ the 100-year IPCC global warming potentials (GWP) are used in (IPCC [36]). The 100-year GWP is a metric used to describe the time-integrated radiative characteristics of well mixed greenhouse gases over a 100-year time horizon. For the sugar production from beet cultivation, the 'Recipe Midpoint (H)' [37] (v1.12), method based on the GWP100 (100-year timeframe), was also used to analyse the impact categories of marine eutrophication and freshwater eutrophication, as they are relevant in the production of a substance derived from a cultivated biomass feedstock, as it is the case of this study (sugar beet) thanks to the primary data information. The latter impact categories could not be used in all the study, as this information was not found in the literature for the other steps [26]. The characterization factors for each emission used are shown in Supporting Information. The analysis was developed following the LCA methodology, which is standardised in the ISO 14040-14044 series by the International Organization of Standardization (ISO 14040-14044 [38, 39]). Sensitivity analysis was developed on sugar production from sugar beet cultivation as primary data were added for PE_100\% production compared to the other polyesters (PE_75\% and PE_Fossil). This analysis was tested through different LCA calculation allocations such as economic and energy. The functional unit is one $\mathrm{kg}$ of $100 \%$ biobased polyester binder, the basis to compare partial biobased polyester versus fossil-based polyester.

\section{Data Used in the Study}

As it is mentioned before in Table 1 and in the previous work, the monomers (except FDCA) were selected according to their primary data availability in the Ecoinvent database version 3.2, and in the open literature for the study of life cycle on polyesters. As for FDCA production, in the two first steps (beet cultivation and sugar production), the analysis was performed with the most recent, primary and detailed data provided by Nordic Sugar A/S, Örtofta Sugar Factory, Sweden during the campaign of 2015. Emissions to air derived from crop management were calculated by the IPCC method (2006) (IPCC [40]) to obtain the atmospheric emissions that are the precursors of climate change (carbon dioxide, nitrous oxide, methane). In the development of this calculation of emissions, some secondary data obtained from the literature [41] were used, as it is the case of the amount of nitrogen in animal manure, which was applied on the soil for sugar beet cultivation. Emissions to water derived from crop management were based on literature data including regional specific climate and soil conditions and some assumptions were applied. The gross nitrogen leaching was estimated to be expressed as $30 \mathrm{~kg} \mathrm{~N}$ per hectare per year [42] and the gross phosphorous leaching was estimated to be expressed as $0.5 \mathrm{~kg} P$ per hectare per year [42]. The data used in the FDCA production's last 3 steps (see Fig. 2) were secondary obtained by Eerhart's work [24]. Some assumptions were needed in the conversion of fructose step for the impact category of GHG emissions. The energy that was considered was natural gas (same energy that was used in the sugar production step). Finally, all data were incorporated into the SimaPro LCA software, and into the Ecoinvent database version 3.2 with an attributional system model that was used as a background source in some processes for FDCA production and the polyester binders. Whenever it was possible, models based on European technology (RER) were used within the system; however, some processes had models based only on the rest of the world's technology (ROW). In this case, they were used as a substitute to Europe's based models. The LCA limitations of each impact category for the PE_100\% including the FDCA are summarized in Table 2. Inventory analysis for the PE_100\% according to the composition shown in Table 3 and the relevant data for the FDCA
Table 2 The LCA limitations of each impact category for all polyesters and FDCA

\begin{tabular}{lll}
\hline & Impact categories & LCA limitations \\
\hline PE_100\% & GHG emissions & Secondary data information in literature \\
& NREU & \\
PE_75\% & GHG emissions & Secondary data information in literature \\
& NREU & \\
PE_Fossil & GHG emissions & Secondary data information in literature \\
& NREU & \\
FDCA & GHG emissions & Secondary data information in literature \\
& NREU & \\
SUGAR PRODUCTION FROM & GHG emissions (support- & Primary data information (our study) \\
SUGAR BEET CULTIVATION & ing information) & \\
& NREU (supporting infor- & \\
& mation) & \\
& Marine eutrophication & \\
& Freshwater eutrophica- & \\
& tion & \\
\hline
\end{tabular}


Table 3 Inventory analysis for $1 \mathrm{~kg}$ of PE_100\% production.

The data not shown in the table are from Ecoinvent. Energy refers the non-renewable energy use in each monomer
Table 4 Relevant data on process data for $1 \mathrm{~kg}$ of FDCA production from sugar beet cultivation. The inventory analysis for the sugar production is presented in Supporting Information

\begin{tabular}{lllllll}
\hline Polyester binder & Input & \multicolumn{5}{l}{ Output } \\
\hline PE_100\% & Materials & & Unit & Materials & Unit \\
& Gly Bio & 0.07 & $\mathrm{~kg}$ & PE & 1.00 & $\mathrm{~kg}$ \\
& $1,3-\mathrm{PD}$ & 0.34 & $\mathrm{~kg}$ & & & \\
FDCA & 0.39 & $\mathrm{~kg}$ & & & \\
& SA & 0.21 & $\mathrm{~kg}$ & & & \\
Energy & & & Emissions to air & & \\
Gly Bio & - & & Gly Bio & 0.74 & $\mathrm{~kg} \mathrm{CO}_{2}$ eq \\
& $1,3-\mathrm{PD}$ & 21.80 & MJ & $1,3-\mathrm{PD}$ & 0.45 & $\mathrm{~kg} \mathrm{CO}_{2}$ eq \\
& FDCA & 6.14 & MJ & FDCA & 0.18 & $\mathrm{~kg} \mathrm{CO}_{2}$ eq \\
& SA & 6.76 & MJ & SA & & \\
\end{tabular}

\begin{tabular}{lll}
\hline GHG emissions & & \\
Sugar from beet (calculated) & 0.71 & $\mathrm{~kg} \mathrm{CO}_{2} \mathrm{eq} / \mathrm{kg}$ sugar \\
Fructose from sugar (assumption) & 0.23 & $\mathrm{~kg} \mathrm{CO}_{2} \mathrm{eq} / \mathrm{kg}$ fructose \\
FDCA from fructose (literature [24]) & 0.24 & $\mathrm{~kg} \mathrm{CO}_{2} \mathrm{eq} / \mathrm{kg}$ FDCA \\
TOTAL GHG emissions FDCA from sugar beet & 1.18 & $\mathrm{~kg} \mathrm{CO}_{2} \mathrm{eq} / \mathrm{kg}$ FDCA \\
NREU & & \\
Sugar from beet (calculated) & 7.11 & $\mathrm{MJ} / \mathrm{kg}$ sugar \\
Fructose from sugar (literature [24]) & 3.90 & $\mathrm{MJ} / \mathrm{kg}$ fructose \\
FDCA from fructose (literature [24]) & 5.00 & $\mathrm{MJ} / \mathrm{kg}$ FDCA \\
TOTAL NREU FDCA from sugar beet & 16.0 & $\mathrm{MJ} / \mathrm{kg}$ FDCA \\
\hline
\end{tabular}

production is also shown in Table 4 . The inventory analysis for PE_75\% and PE_Fossil is shown in Garcia Gonzalez et al. [26].

\section{Allocation on Sugar Production}

Allocation is required in the sugar production step for the obtainment of FDCA; the procedure defined by ISO 14044 is followed. Seven output flows are obtained in the sugar production, which are white sugar, molasses, dried sugar beet pulp (pellets), pressed sugar beet pulp, carbonation lime presses and energy as steam (energy drying) and heat (energy heating) (see Supporting Information for a detailed explanation). Allocation of impacts is a very important methodological issue of LCA practitioners and its definition is 'Partitioning the input or output flows of a process or a product system between the product system under study and one or more other product systems' (ISO 14040-14044) $[38,39]$. Two different types of allocations, economic and energy, were studied and their allocation applications for the seven outputs are shown in Table 5. Both allocations were selected by some fundamental reasons: in the energy case, it was assessed due to the fact that sugar mills globally exist, which are bioethanol producers and therefore, an energetic purpose makes it a suitable alternative for this study even though in our specific case it is not produced. In
Table 5 The different percentages of the two applied allocations in sugar production from beet cultivation

\begin{tabular}{lll}
\hline Product/by-products & $\begin{array}{l}\text { Economic allocation } \\
{[\mathrm{EA}](\%)}\end{array}$ & $\begin{array}{l}\text { Energy alloca- } \\
\text { tion [EnA] } \\
(\%)\end{array}$ \\
\hline White sugar & 90.0 & 81.6 \\
Pellets & 4.9 & 10.9 \\
Pressed sugar beet pulp & 0.8 & 0.4 \\
Molasses & 3.5 & 6.0 \\
Energy drying & 0.5 & 0.7 \\
Energy heating & 0.2 & 0.6 \\
\hline
\end{tabular}

the economic case, it was evaluated by its simplicity and ability to illustrate the properties of complex systems notwithstanding the prices may change over the years and an extended estimated price to a longer period and periodic controls may be needed to enhance its credibility. The data used for energy allocation (EnA) was completely primary. In the case of economic allocation (EA), secondary data were needed for energy outputs obtained from the literature [43-45]. The rest of outputs were primary. EA was assessed in accordance with an estimated average price from the last ten years for sugar and the last five years for by-products that are produced at the factory. EnA was developed according 
to the amount of energy as low heating value in sugar and the other by-products. Carbonation lime presses output was excluded in the allocation analysis due to its insignificant value for economic allocation and lack of energy content for energy allocation. The price and energy value for each product were multiplied by the amount in tons of dry matter of each product to obtain the allocation percentage. For the rest of the study, regarding FDCA production, the results from economic allocation were selected as base case and used due to its more effective way to attribute mass and energy outputs to the same unit. Moreover, there were no remarkable differences in the results between both allocations as it is shown in the percentage of sugar in Table 5. The results of sugar production from sugar beet cultivation in terms of GHG emissions, NREU and eutrophication for both allocations are presented in Supporting Information.

\section{Results and Discussion}

\section{Solubility Characterization on $100 \%$ Bio-based Polyester Binder}

In coating technology, a dilution solvent is normally needed in order to reduce the viscosity and to allow a correct film forming mechanism. In our previous work [26], dilution with butyl acetate (BA) was adequate for PE_75\% and PE_Fossil formulations. However, more polar solvents are needed for PE_100\% containing the FDCA monomer. Among the various solvents tested such as propylene carbonate (PPC), acetonitrile (AN), acetone (AC), tetrahydrofuran (THF) and butyl acetate (BA), PPC was chosen as an optimal solution. Moreover, PPC is considered an environmentally friendly solvent for the development of the sustainable coating [46]. The solubility parameter $(\delta)$ of the PCC solvent is $27.2 \delta /$ $\mathrm{MPa}^{1 / 2}$ whereas the BA solvent has a $17.4 \delta / \mathrm{MPa}^{1 / 2}$ of solubility parameter [47]. Those different parameters suggest that PE_100\% binder is significantly more polar than the other two resins.

\section{Characterization on $100 \%$ Bio-based Polyester Binder}

The characterization of the $100 \%$ bio-based polyester binders after the copolymerization compared to PE_75\% and PE_Fossil is shown in Table 6. The number average molecular weight $(\mathrm{Mn})$ of the polyesters ranged from 1285 to $1775 \mathrm{~g} / \mathrm{mol}$ and the weight average molecular weight (Mw) from 2578 to $4328 \mathrm{~g} / \mathrm{mol}$ with a polydispersity index (PDI) between 1.8 and 2.5. All these values are suitable given the nature of polycondensation polymers. The glass-transition temperatures $(\mathrm{Tg})$ of the copolyesters is represented in Table 6. The PE_100\% and PE_75\% binders showed a
Table 6 PE binder's characterization. Molecular weights (Mn and $\mathrm{Mw}$ ), polydispersity index (PDI) and acid number (AV) of all PE binders

\begin{tabular}{llllll}
\hline Samples & $\operatorname{Tg}\left({ }^{\circ} \mathrm{C}\right)$ & Mn (g/mol) & Mw (g/mol) & PDI & $\begin{array}{l}\text { AV (mg } \\
\text { KOH/g) }\end{array}$ \\
\hline PE_100\% & -8 & 1775 & 3138 & 1.8 & 14.4 \\
PE_75\% & -13 & 1285 & 2578 & 2 & 12.8 \\
PE_Fossil & 6 & 1726 & 4328 & 2.5 & 6.8 \\
\hline
\end{tabular}

more flexible resin compared to PE_Fossil. According to the substitution of Pht with FDCA, a small difference between bio-based polyesters was observed, being a bit less flexible PE_ $100 \%\left(-8{ }^{\circ} \mathrm{C}\right)$.

\section{Characterization on PU Coating Based on FDCA}

Table 7 shows the characterization of the crosslinked PU1 coating compared to PU2 and PU3 properties. Substituting the Pht monomer with FDCA monomer, a stiffer PU1 polymer backbone is formed, with a $\mathrm{Tg}$ value of $+14{ }^{\circ} \mathrm{C} \mathrm{com}$ pared to $+3{ }^{\circ} \mathrm{C}$ for PU2. It is due to the fact that the FDCA structure is more symmetric and regular, which makes the interaction between the polymer's chains become stronger and a raising of $\mathrm{Tg}$ was shown. When comparing the previous coatings, the fossil-based PU3 one, showed the highest $\mathrm{Tg}$ by around $+34^{\circ} \mathrm{C}$, which contains 1,2-PD monomer as a chain extender, with methyl side groups, and therefore it shows a less flexible polymer structure. As the indentation behaviour is concerned, the PU1 coating with FDCA-based polyester binder showed the highest hardness between the bio-based coatings (PU1 and PU2), which is in agreement with its higher Tg. However, the 100\%fossil-based PU3 coating presented the highest hardness, also in agreement with its $\mathrm{Tg}$. In respect of surface wettability, the contact angle showed a more hydrophilic character for PU1 $\left(80^{\circ}\right)$ whereas PU2 showed a moderately hydrophobic character $\left(88^{\circ}\right)$. The reason may be caused by the more polar character of FDCA with respect to phthalic structures. The adhesion test was evaluated onto glass and chromated aluminium. Both PU coatings applied onto glass and Al chromed substrates showed an excellent adhesion with the highest bonding strength observed on PU1 coating ( $>8 \mathrm{MPa}$ ), which is in agreement with its hydrophilic character. In Table 8 , the surface tension on all PU coatings is reported. PU1 also showed the highest surface tension value by around 43.3 $\mathrm{mN} / \mathrm{m}$ constituting greater cohesive forces and therefore greater forces of adhesion, which is in agreement with the adhesion test results.

As a last test, the hydrolytic stability test was also assessed and monitored over 30 days of continuous exposure to water at $+60{ }^{\circ} \mathrm{C}$. Contact angle and hardness measurements were used to control the quantitative evaluation 
Table 7 Coating characterization

\begin{tabular}{|c|c|c|c|c|c|}
\hline \multirow[t]{2}{*}{ PU coating } & \multirow[t]{2}{*}{$\operatorname{Tg}\left({ }^{\circ} \mathrm{C}\right)$} & \multirow[t]{2}{*}{ OCA TEST $\left(^{\circ}\right)$} & \multicolumn{2}{|c|}{ Adhesion test (MPA) } & \multirow[t]{2}{*}{ Hardness test (ób) } \\
\hline & & & Glass & Al Chromed & \\
\hline PU1 & 14.0 & $80.0 \pm 2.1$ & $>8$ & $1.3 \pm 0.3$ & $83.3 \pm 0.1$ \\
\hline PU2 [26] & 3.0 & $88.0 \pm 3.4$ & $6.4 \pm 1.2$ & $1.0 \pm 0.2$ & $54.1 \pm 0.2$ \\
\hline PU3_Fossil [26] & 34.0 & $83.0 \pm 1.8$ & $7.3 \pm 2.3$ & $1.1 \pm 0.4$ & $91.0 \pm 0.4$ \\
\hline
\end{tabular}

Table 8 Surface tension and its components determined for the PU coating substrates using $\mathrm{Wu}$ method calculation

\begin{tabular}{llll}
\hline Samples & $\begin{array}{l}\text { SFT Polar } \\
(\mathrm{mN} / \mathrm{m})\end{array}$ & $\begin{array}{l}\text { SFT Dispersive } \\
(\mathrm{mN} / \mathrm{m})\end{array}$ & $\begin{array}{l}\text { SFT } \\
\text { total } \\
(\mathrm{mN} / \mathrm{m})\end{array}$ \\
\hline PU1 & 9.7 & 33.6 & 43.3 \\
PU2 & 6.7 & 32.2 & 38.9 \\
PU3 & 8.9 & 32.8 & 41.7 \\
\hline
\end{tabular}

every 5 days. The results are shown in Fig. 3 and they are expressed as percentage retention of the property over the time. A fast decrease of hardness with a value of $40 \%$ less is observed for PU1 after the 5th day monitored by indentation hardness test and it is maintained during the following 30 days. With contact angle test (Fig. 3b), a slight decrease of hydrophobicity is observed in PU1 film during the first 10 days of testing, which are comparable to PU2 and PU3. After the 20th day of testing the hydrophobicity faster decrease reaching 15\% less being distanced from PU2 and PU3. This test may confirm the hydrophilic character of the PU1 based on FDCA. A hydrophilic material can absorb water faster swelling the material and therefore, decreasing the hardness.

\section{Environmental Impact Assessment}

The total NREU and GHG emissions of the three cases were evaluated for $1 \mathrm{~kg}$ of polyester and calculated according to the composition of the synthesised polyesters (Table 1). Figure 4a shows the total impact of the GHG emissions with a value of $2.75 \mathrm{~kg} \mathrm{CO}$ eq/ $/ \mathrm{kg}$ for PE_75\% whereas PE_100\% has a lower impact with a value of $1.75 \mathrm{~kg} \mathrm{CO}_{2} \mathrm{eq} / \mathrm{kg}$. Both show a meaningful reduction compared to PE_Fossil by around $67 \%$ and $79 \%$ respectively $\left(8.4 \mathrm{~kg} \mathrm{CO}_{2} \mathrm{eq} / \mathrm{kg}\right)$. The substitution of the phthalic monomer with FDCA into the PE_100\%, led to a significant reduction in the latter by around $36 \%$ including the polymerization process. As for the total NREU, Fig. $4 \mathrm{~b}$ shows a value of $96 \mathrm{MJ} / \mathrm{kg}$ for PE_Fossil, a $62.5 \mathrm{MJ} / \mathrm{kg}$ for PE_75\% and a $39 \mathrm{MJ} / \mathrm{kg}$ for PE_100\% where PE_100\% shows a significantly lower impact than PE_75\% (-38\%) and PE_Fossil (-60\%).

\section{Environmental Impacts on Sugar Production}

The total phosphate and nitrate contributions of the different steps of the sugar production process from beet cultivation is detailed in this part of the study in Fig. 5. They were evaluated for the reference of 1 ton sugar for both allocations. The phosphorus in phosphate form in the freshwater with a total value of $0.19 \mathrm{~kg} \mathrm{PO}_{4}{ }^{3-} \mathrm{eq} /$ ton sugar for the economic allocation and $0.18 \mathrm{~kg} \mathrm{PO}_{4}{ }^{3-}$ eq/ton sugar for energy

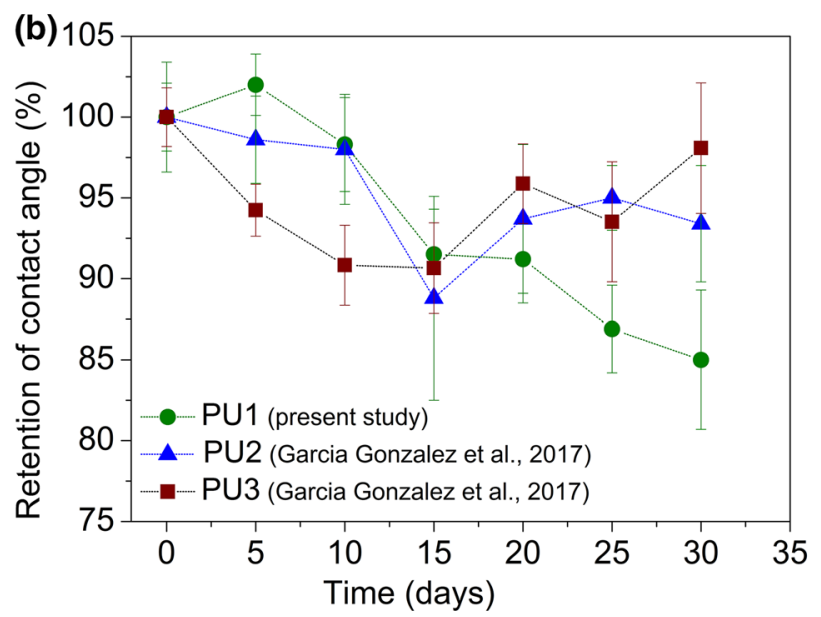

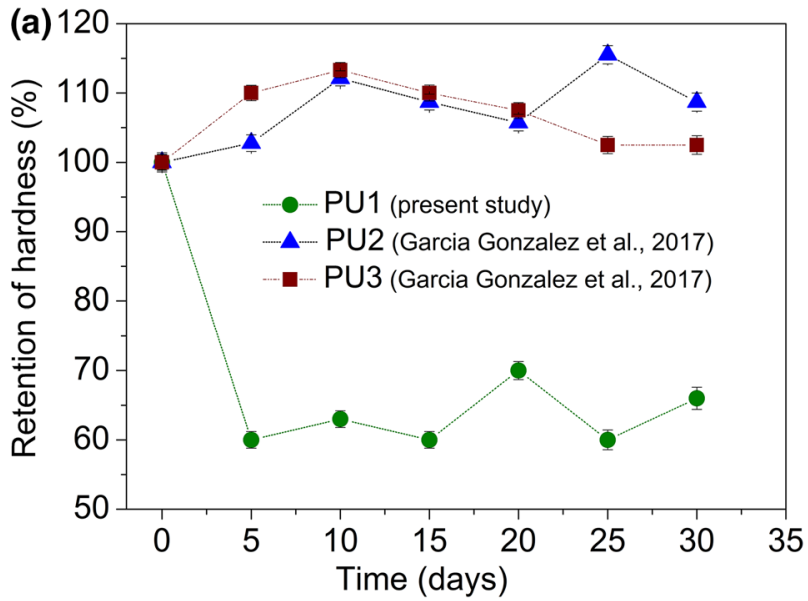

Fig. 3 Hydrolytic stability monitoring by $\mathbf{a}$ hardness and $\mathbf{b}$ contact angle tests 


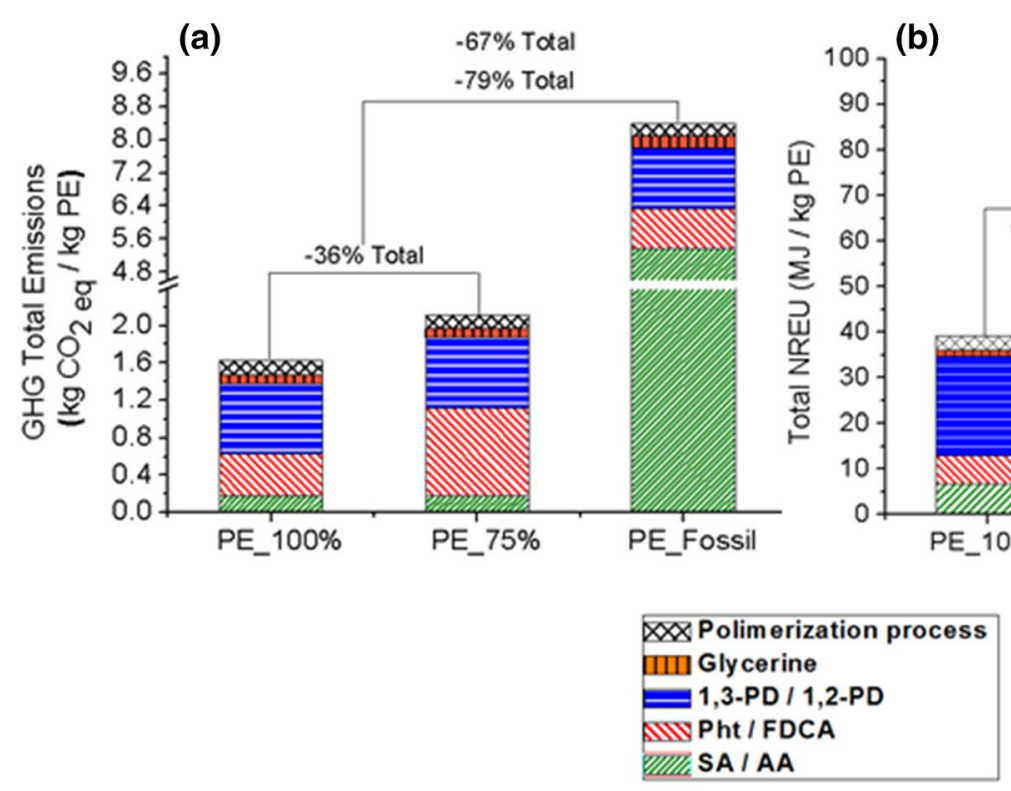

Fig. 4 a Total impact of the GHG emissions and b total NREU for PE_100\% Bio-based compared to PE_75\% Bio-based and PE_Fossil-based

Fig. 5 The total a phosphate and $\mathbf{b}$ nitrate contributions of all the steps of the sugar production (a)

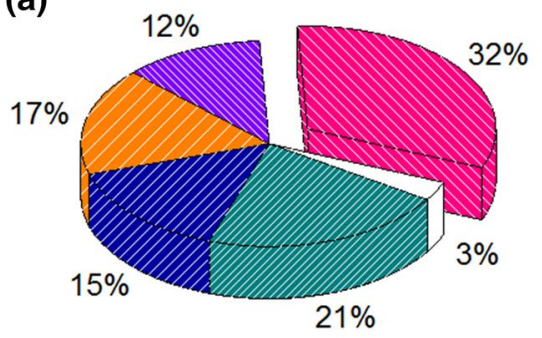

(b)

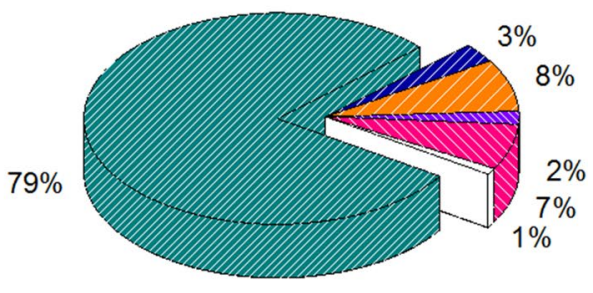

Emissions from sugar beet cultivation

VIII Machinery used in agricultural stage

Raw materials production (cultivation step)

Beet transport to the sugar factory

Energy consumed (sugar production step)

Chemical products production (sugar production step)

allocation where the $53 \%$ of the total impact corresponds to sugar beet cultivation and the $47 \%$ of the total impact corresponds to sugar production (see Supporting Information). As to the details of this analysis shown in Fig. 5a, those emissions to water mainly come from the energy consumed in the sugar production representing a $32 \%$ of the total impact followed by leaching formation from the beet cultivation ( $21 \%$ of the total). In the case of the energy consumed during the production, this phase represents the biggest impact due to the wastes caused from coal production. However, it should be noted that those emissions do not have a big impact on water due to clay soil, the dominating soil type in the southwest of Sweden, which reduces the phosphorus leakage. Nitrogen in nitrate form was also assessed. The total $\mathrm{NO}_{3}{ }^{-}$emission equivalent to economic allocation presented a value of $3.2 \mathrm{~kg} \mathrm{NO}_{3}{ }^{-} \mathrm{eq} / \mathrm{ton}$ sugar and almost the same value for energy allocation (3.0 $\mathrm{kg} \mathrm{NO}_{3}{ }^{-}$eq/ton sugar) as shown in Supporting Information. Figure 5b shows that $79 \%$ of these total emissions derive from the emissions to water as a consequence of leaching formation. The reason is the big amount of nitrogen used in fertilizers. The rest of the steps show a lower percentage of $9 \%$ being less representative. The total NREU and the total impact of GHG emissions in sugar production for all allocations were also studied and are shown in Supporting Information. 


\section{Conclusions}

A new class of $100 \%$ bio-based polyester binder based on FDCA as precursors for PU coatings was re-designed and obtained through the selection and copolymerization of four different bio-monomers and cross-linked with a conventional IPDI based hardener. The technological evaluation showed a stiffer PU1 coating and a more hydrophilic character leading to better adhesion but also to a more moisture-sensitive surface. Potential applications may be interesting in the field of metal coating (coil coating, automotive), especially as intermediate layers/primers where the high adhesion of the material and recoatability are needed. The evaluation of the environmental impacts related to the production of the $100 \%$ bio-based polyester binder based on FDCA was applied in terms of GHG emissions and NREU. The substitution of Pht monomer with FDCA monomer in PE_100\% compared to partial bio-based polyester (PE_75\%) may reduce the total GHG emissions and NREU by around 36\% and 38\% respectively. In addition, a very remarkable reduction was showed for PE_100\% compared to fossil-based polyester with a percentage of $79 \%$ in terms of GHG emissions and $60 \%$ in terms of NREU. However, other environmental burdens should be also studied to go deeper into this work.

Acknowledgements The authors would like to acknowledge the financial support of project "Sustainable Manufacturing" (CTNO1_00163_148175) and gratefully acknowledge Gigliola Clerici for support with thermal analysis in the research. Parts of the study were performed within the framework of the project Farm2Furan, funded by the Swedish Research Council Formas, where Nordic Sugar A/S and Nordic Sugar A/S, Technology \& Innovation are kindly acknowledged for providing all primary data for the LCA on sugar production from sugar beet cultivation.

Open Access This article is distributed under the terms of the Creative Commons Attribution 4.0 International License (http://creativeco mmons.org/licenses/by/4.0/), which permits unrestricted use, distribution, and reproduction in any medium, provided you give appropriate credit to the original author(s) and the source, provide a link to the Creative Commons license, and indicate if changes were made.

\section{References}

1. Zia KM, Bhatti HN, Ahmad Bhatti I (2007) Methods for polyurethane and polyurethane composites, recycling and recovery: a review. React Funct Polym 67:675-692

2. Benyahya S, Boutevin B, Caillol S, Lapinte V, Habas JP (2012) Optimization of the synthesis of polyhydroxyurethanes using dynamic rheometry. Polym Int 6:918-925

3. Pfister DP, Xia Y, Larock RC (2011) Recent advances in vegetable oil-based polyurethanes. Chem Sus Chem 4:703-717

4. Vilela C, Sousa AF, Fonseca AC, Serra AC, Coelho JFJ, Freire CSR, Silvestre AJD (2014) The quest for sustainable polyestersinsights into the future. Polym Chem 5:3119-3141
5. Noreen A, Zia KM, Zuber M, Tabasum S, Zahoor AF (2016) Biobased polyurethane: an efficient and environment friendly coating systems: a review. Prog Org Coat 91:25-32

6. Ragauskas AJ, Williams CK, Davison BH, Britovsek G, Cairney J, Eckert CA, Frederick Jr, Hallett JP, Leak DJ, Liotta CL, Mielenz JR, Murphy R, Templer R, Tschaplinski T (2006) The path forward for biofuels and biomaterials. Science 311:484-489

7. Helou M, Carpentier J-F, Guillaume S (2011) Poly(carbonateurethane): an isocyanate-free procedure from a,x-di(cyclic carbonate) telechelic poly(trimethylene carbonate)s. Green Chem 13:266-271

8. Annunziata L, Diallo AK, Fouquay S, Michaud G, Simon F, Brusson J-M, Carpentier J-F, Guillaume SM (2014) $\alpha, \omega$-Di(glycerol carbonate) telechelic polyesters and polyolefins as precursors to polyhydroxyurethanes: an isocyanate-free approach. Green Chem 16:1947-1956

9. Van Velthoven JLJ, Gootjes L, Van Es DS, Noordover BAJ, Meuldijk J (2015) Poly(hydroxy urethane)s based on renewable diglycerol dicarbonate. Eur Polym J 70:125-135

10. Zhang C, Ding R, Kessler MR (2014) Reduction of epoxidized vegetable oils: a novel method to prepare bio-based polyols for polyurethanes. Macromol Rapid Commun 35:1068-1074

11. Van Putten RJ, Van Der Waal JC, De Jong E, Rasrendra CB, Heeres HJ, De Vries JG (2013) Hydroxymethylfurfural, a versatile platform chemical made from renewable resources. Chem Rev 113:1499-1597

12. Tong X, Ma Y, Li Y (2010) Biomass into chemicals: conversion of sugars to furan derivatives by catalytic processes. Appl Catal A Gen 385:1-13

13. Sousa AF, Vilela C, Fonseca AC, Matos M, Freire CSR, Gruter GJM, Coelho JFJ, Silvestre AJD (2015) Biobased polyesters and other polymers from 2,5-furandicarboxylic acid: a tribute to furan excellency. Polym Chem 6:5961-5983

14. Cao M, Zhang C, He B, Huang M, Jiang S (2017) Synthesis of 2,5-furandicarboxylic acid-based heat-resistant polyamides under existing industrialization process. Macromol Res 25:722-729

15. Wilsens CHRM., Verhoeven JMGA., Noordover BAJ, Hansen MR, Auhl D, Rastogi S (2014) Thermotropic polyesters from 2,5-furandicarboxylic acid and vanillic acid: synthesis, thermal properties, melt behavior, and mechanical performance. Macromolecules 47:3306-3316

16. Wu B, Xu Y, Bu Z, Wu L, Li BG, Dubois P (2014) Biobased poly(butylene 2,5-furandicarboxylate) and poly(butylene adipateco-butylene 2,5-furandicarboxylate)s: from synthesis using highly purified 2,5-furandicarboxylic acid to thermo-mechanical properties. Polym 55:3648-3655

17. Kwiatkowska M, Kowalczyk I, Kwiatkowski K, Szymczyk A, Rosłaniec Z (2016) Fully biobased multiblock copolymers of furan-aromatic polyester and dimerized fatty acid: Synthesis and characterization. Polymer 99:503-512

18. Jacquel N, Saint-Loup R, Pascault JP, Rousseau A, Fenouillot F (2015) Bio-based alternatives in the synthesis of aliphaticaromatic polyesters dedicated to biodegradable film applications. Polymer 59:234-242

19. Wang J, Liu X, Jia Z, Liu Y, Sun L, Zhu J (2017) Synthesis of biobased poly(ethylene 2,5-furandicarboxylate) copolyesters: Higher glass transition temperature, better transparency, and good barrier properties. J Polym Sci Part A 55:3298-3307

20. Zia KM, Noreen A, Zuber M, Tabasum S, Mujahid M (2016) Recent developments and future prospects on bio-based polyesters derived from renewable resources: a review. Int J Biol Macromol 82:1028-1040

21. Yu Z, Zhou J, Cao F, Wen B, Zhu X, Wei P (2013) Chemosynthesis and characterization of fully biomass-based copolymers of ethylene glycol, 2,5-furandicarboxylic acid, and succinic acid. J Appl Polym Sci 130:1415-1420 
22. Papageorgiou GZ, Papageorgiou DG, Terzopoulou Z, Bikiaris DN (2016) Production of bio-based 2,5-furan dicarboxylate polyesters: Recent progress and critical aspects in their synthesis and thermal properties. Eur Polym J 83:202-229

23. Zhou W, Zhang Y, Xu Y, Wang P, Gao L, Zhang W, Ji J (2014) Synthesis and characterization of bio-based poly(butylene furandicarboxylate)-b-poly(tetramethylene glycol) copolymers. Polym Degrad Stab 109:21-26

24. Eerhart AJJE., Faaij APC, Patel MK (2012) Replacing fossil based PET with biobased PEF; process analysis, energy and GHG balance. Energy Environ Sci 5:6407-6422

25. Isola C, Sieverding HL, Raghunathan R, Sibi MP, Webster DC, Sivaguru J, Stone JJ (2017) Life cycle assessment of photodegradable polymeric material derived from renewable bioresources. $\mathbf{J}$ Clean Prod 142:2935-2944

26. Garcia Gonzalez MN, Levi M, Turri S (2017) Development of polyester binders for the production of sustainable polyurethane coatings: technological characterization and life cycle assessment. J Clean Prod 164:171-178

27. ASTM D4752-10 (2015) Standard Practice for Measuring MEK Resistance of Ethyl Silicate. (Inorganic) Zinc-Rich Primers by Solvent Rub

28. Jungbluth N, Dinkel F, Doka G, Chudacoff M, Dauriat A, Spielman M, Sutter J, Kljun N, Keller M, Schleiss K (2007) Life cycle inventories of bioenergy. Ecoinvent report No. 17. Swiss Centre for LCI, Dübendorf

29. http://www.duponttateandlyle.com/sites/default/files/Susterra $\% 20$ LCA.pdf. Accessed 01 Nov 2017

30. Althaus H-J, Chudacoff M, Hischier R, Jungbluth N, Osses M, Primas A (2007) Life Cycle Inventories of Chemicals. Ecoinvent report No. 8. Swiss Centre for LCI, Dübendorf

31. Cok B, Tsiropoulos I, Roes AL, Patel MK (2014) Succinic acid production derived from carbohydrates: an energy and greenhouse gas assessment of a platform chemical toward a bio-based economy. Biofuels Bioprod Biorefining 8:16-29

32. ASTM D4541 (2009) Standard test method for pull-off strength of coatings using portable adhesion testers

33. ISO 2815:2003 (2003) Paints and varnishes-Buchholz indentation test

34. Wu S (1973) Polar and nonpolar interactions in adhesion. J Adhes 5:39-55

\section{Affiliations}

\section{María Nelly García González ${ }^{1,2}$. Pål Börjesson ${ }^{2} \cdot$ Marinella Levi $^{1} \cdot$ Stefano Turri ${ }^{1}$}

\section{María Nelly García González}

marianelly.garcia@polimi.it;

nelly.garcia_gonzalez@miljo.lth.se

1 Department of Chemistry, Materials and Chemical

Engineering "Giulio Natta", Politecnico di Milano, Piazza

Leonardo da Vinci 32, 20133 Milan, Italy
35. Frischknecht R, Jungbluth N, Althaus H-J, Doka G, Heck T, Hellweg S, Hischier R, Nemecek T, Rebitzer G, Spielmann M, Wernet G (2007) Overview and methodology. Ecoinvent report No. 1. Swiss Centre for LCI, Dübendorf

36. IPPC Intergovernmental Panelon Climate (2007) IPCC Fourth Assessment Report, Climate Change, https://ipcc.ch/publicatio ns_and_data/ar4/syr/en/contents.html. Accessed 01 Nov. 2017

37. http://www.leidenuniv.nl/cml/ssp/publications/recipe_characteri sation.pdf Accessed 01 Nov. 2017

38. ISO 14040:2006 (2006) Environmental management-life cycle assessment-principles and framework. Geneva

39. ISO 14044: 2006 (2006) Environmental management-life cycle assessment-requirements and guidelines. Geneva

40. IPCC Guidelines for National Greenhouse Gas Inventories, vol 4, Chap. 11 (2006). http://www.ipcc-nggip.iges.or.jp/public/2006gl/ vol4.html. Accessed 01 Nov. 2017

41. http://www.greppa.nu/om-greppa/om-projektet/in-english.html. Assessed 01 Nov. 2017

42. Börjesson P, Tufvesson LM (2011) Agricultural crop-based biofuels-resource efficiency and environmental performance including direct land use changes. J Clean Prod 19:108-120

43. http://www.scb.se/en/finding-statistics/statistics-by-subject-area/ energy/price-trends-in-the-energy-sector/energy-prices-on-natur al-gas-and-electricity/pong/tables-and-graphs/average-prices-byhalf-year-2007/prices-on-natural-gas-for-industrial-consumers2007/. Assessed 01 Nov. 2017

44. Lundgren J, Ekbom T, Hulteberg C, Larsson M, Grip CE, Nilsson L, Tunå P (2013) Methanol production from steel-work off-gases and biomass based synthesis gas. Appl Energy 112:431-439

45. Börjesson P, Lantz M, Andersson J, Björnsson L, Möller BF, Fröberg M, Hanarp P, Hulteberg C, Iverfeldt E, Lundgren J (2017) Methane as vehicle fuel-a well to wheel analysis. The Swedish Knowledge Centre for Renewable Transportation Fuels

46. Demire Y (2015) Sustainability and economic analysis of propylene carbonate and polypropylene carbonate production processes using $\mathrm{CO}_{2}$ and propylene oxide. J Chem Eng Process Technol 6:236

47. Barton AFM (1985) Handbook of solubility parameters and other cohesion parameters. CRC Press Inc, Florida 